\title{
Comparative Assessment of ADA, IDRS, and FINDRISC in Predicting Prediabetes and Diabetes Mellitus in South Indian Population
}

\author{
Parveen Doddamani $^{1} \quad$ Nitin Ramanathan ${ }^{1} \quad$ N. K. Swetha ${ }^{1} \quad$ M. N. Suma ${ }^{1}$ \\ 1Department of Biochemistry, JSS Medical College and Hospital, \\ JSS Academy of Higher Education and Research, Bannimantap, \\ Address for correspondence N. K. Swetha, MD, Department \\ of Biochemistry, JSS Medical College and Hospital, JSS Academy \\ Mysuru, Karnataka, India \\ of Higher Education and Research, Shivarathreeshwaranagar, \\ Bannimantap, Mysuru 570015, Karnataka, India \\ (e-mail: drswethasuresh@gmail.com).
}

J Lab Physicians 2021;13:36-43.

\begin{abstract}
Introduction Diabetes risk-screening tools are validated and implemented across various countries. There is a need for improvement in these risk scores with suitable modifications so as to make them more sensitive, specific, and suitable to the local population.

Objectives The aim of this study was to evaluate and compare the diagnostic accuracy and clinical utility of the Indian diabetes risk score (IDRS), the American diabetic association (ADA) risk score, and the Finnish Diabetes Risk Score in healthy subjects of South Indian origin in predicting the risk of diabetes and to correlate these risk scores with the blood glucose and hemoglobin A1c (HbA1c) levels in the study population.

Materials and Methods A total of 160 subjects attending the master health checkup/outpatient department of a tertiary care hospital were included in the study. Each subject was asked to fill a questionnaire. Details obtained using the questionnaire were assessed as per the three diabetic risk scores. Fasting blood sugar/random blood sugar and $\mathrm{HbA} 1 \mathrm{c}$ were estimated.

Statistical Analysis Used Data analysis was done using SPSS 22/23. Pearson correlation was used to compare continuous variables, with $p<0.05$ considered statistically significant. Sensitivity, specificity, positive predictive value, negative predictive value, positive likelihood ratio, negative likelihood ratio, and Mitchell's clinical utility indices were calculated for each risk tool.

Keywords

- ADA risk score

- IDRS

- prediabetes

- diabetes risk scores

- FINDRISC

Results We found the prevalence of diabetes to be $11.9 \%$. ADA risk score was the only risk score that showed a statistically significant difference $(p$-value $=0.05)$ between the low- and high-risk subjects.

Conclusions ADA or IDRS risk scores can be used for screening diabetes in the South Indian population. We suggest that inclusion of the history of gestational diabetes and hypertension in the IDRS risk score might improve its sensitivity as a screening tool in our local population.
\end{abstract}

published online May 24, 2021
DOI https://doi.org/

$10.1055 / \mathrm{s}-0041-1727557$ ISSN 0974-2727
C 2021 . The Indian Association of Laboratory Physicians.

This is an open access article published by Thieme under the terms of the Creative Commons Attribution-NonDerivative-NonCommercial-License, permitting copying and reproduction so long as the original work is given appropriate credit. Contents may not be used for commercial purposes, or adapted, remixed, transformed or built upon. (https://creativecommons.org/licenses/by-nc-nd/4.0/).

Thieme Medical and Scientific Publishers Pvt. Ltd. A-12, 2nd Floor, Sector 2, Noida-201301 UP, India 


\section{Introduction}

Diabetes mellitus is rampant in developing countries, and India is named the diabetes capital of the world with the prevalence of 77 million. According to the International Diabetes Federation 2019, the global prevalence of diabetes is 463 million and is expected to increase to 700 million by 2045 . The various causes contributing to this exponential increase are multiple risk factors attributing to diabetes mellitus, a prolonged presymptomatic stage in $>50 \%$ of patients and usually present to the physician with complications and irreversible damage. ${ }^{1,2}$ Hence, early diagnosis and management are important in delaying the progression and complication of the disease, in addition to preventing socioeconomic burden. ${ }^{3}$

Although WHO does not advocate any specific screening programs, it recommends an organization of programs specific to particular regions/countries; this aims at targeting the local population so as to identify persons who are at high risk. Diabetes risk score system using a simple questionnaire utilizing noninvasive variables has been a time-tested and cost-effective screening tool, which can be applied to screen a large population which is still undiagnosed of diabetes mellitus, though increasing evidence suggests risk scores cannot be generalized from one country to another but can be modified as per the requirement of the local population. ${ }^{4-6}$

The two popular internationally accepted risk scores are the American Diabetes Association (ADA) (-Table 1) and the Finnish Diabetic Risk Score (FINDRISC) (- Table 2) ${ }^{4-6}$ In India, Indian Diabetic Risk Score (IDRS), as shown in (-Table 3) developed by Chennai Urban Rural Epidemiology Study (CURES) cohort study, has been validated across various parts of India and accepted and endorsed by various studies. To our knowledge, there are no studies that have compared these three screening questionnaires in the South Indian population; hence, the comparison is vital. In this study, we aim to screen healthy subjects for the risk of diabetes mellitus type 2 with these three standard risk test questionnaires. ${ }^{7.8}$

\section{Objectives}

1. To assess and compare the diagnostic utility of IDRS, ADA risk score, and FINDRISC in predicting the risk of diabetes mellitus in healthy subjects of South Indian origin.

2. To correlate these risk scores with the serum glucose and hemoglobin A1c (HbA1c) levels in healthy subjects of South Indian origin.

\section{Materials and Methods}

An observational cross-sectional study was conducted for a 3-month duration between March and May 2019 at a tertiary-care teaching Medical College Hospital. The study was approved by the institutional ethical committee. The reported prevalence of diabetes in India is $8.8 \% .^{1}$ Based on this, the sample size was calculated to be 124 , with a precision of $5 \%$ and confidence level of $95 \%$. In our study, 160 healthy subjects in the age group of 20 to 70 years, attending the master health checkup (MHC)/outpatient department (OPD), were included using stratified random sampling. Exclusion criteria: known cases of diabetes mellitus type 1 and 2, pregnant females, subjects on steroids or having overt cardiovascular disease (clinical atherosclerosis, atrial fibrillation, heart failure, significant valvular disease), and inability to give informed consent. Method of data collection: All the subjects who provided consent and satisfied the inclusion criteria were requested to answer the questions mentioned in the proforma, which included all the required parameters to fill the three diabetes risk scores: IDRS, ADA risk score, and FINDRISC. Anthropometric measurements were recorded with calibrated instruments according to a standardized protocol. Body mass index (BMI) was measured using the formula: weight $(\mathrm{kg})$ divided by height $\left(\mathrm{m}^{2}\right)$. Further, the criteria for the diagnosis of diabetes mellitus were as follows: fasting plasma glucose $\geq 126 \mathrm{mg} / \mathrm{dL}$ or random plasma glucose $\geq 200 \mathrm{mg} / \mathrm{dL}$ with clinical features of polyphagia, polyuria, polydipsia, and $\mathrm{HbA} 1 \mathrm{c} \geq 6.5 \%{ }^{9}$

Table 1 American Diabetes Association (ADA) risk score ${ }^{5}$

\begin{tabular}{|c|c|}
\hline Particulars & Score \\
\hline \multicolumn{2}{|c|}{ How old are you? } \\
\hline$<40$ & 0 \\
\hline $40-49$ & 1 \\
\hline $50-59$ & 2 \\
\hline$\geq 60$ & 3 \\
\hline \multicolumn{2}{|c|}{ Are you a man or a woman? } \\
\hline Man & 1 \\
\hline Woman & 0 \\
\hline \multicolumn{2}{|c|}{$\begin{array}{l}\text { If you are a woman, have you ever been diagnosed with } \\
\text { gestational diabetes? }\end{array}$} \\
\hline Yes & 1 \\
\hline No & 0 \\
\hline \multicolumn{2}{|c|}{ Do you have a mother, father, sister, or brother with diabetes? } \\
\hline Yes & 1 \\
\hline No & 0 \\
\hline \multicolumn{2}{|c|}{ Have you ever been diagnosed with high blood pressure? } \\
\hline Yes & 1 \\
\hline No & 0 \\
\hline \multicolumn{2}{|c|}{ Are you physically active? } \\
\hline Yes & 0 \\
\hline No & 1 \\
\hline \multicolumn{2}{|c|}{ What is your weight status? Refer the weight chart below } \\
\hline
\end{tabular}

Risk score: If you scored $\geq 5$, you are at an increased risk of having type 2 diabetes. However, only your doctor can tell for sure if you do have type 2 diabetes or prediabetes (a condition that precedes type 2 diabetes, in which blood glucose levels are higher than normal). Talk to your doctor to see if additional testing is needed. 
Table 2 Finnish Diabetes Risk Score (FINDRISC) ${ }^{6}$

\begin{tabular}{|c|c|c|}
\hline \multicolumn{2}{|l|}{ Particulars } & Points/Score \\
\hline \multicolumn{3}{|l|}{ Age $(y)$} \\
\hline \multicolumn{2}{|l|}{$<45 y$} & 0 \\
\hline \multicolumn{2}{|l|}{$45-54$ y } & 2 \\
\hline \multicolumn{2}{|l|}{$55-64$ y } & 3 \\
\hline \multicolumn{2}{|l|}{$>64 y$} & 4 \\
\hline \multicolumn{3}{|c|}{ Body mass index } \\
\hline \multicolumn{2}{|l|}{$<25 \mathrm{~kg} / \mathrm{m}^{2}$} & 0 \\
\hline \multicolumn{2}{|l|}{$25-30 \mathrm{~kg} / \mathrm{m}^{2}$} & 1 \\
\hline \multicolumn{2}{|l|}{$>30 \mathrm{~kg} / \mathrm{m}^{2}$} & 3 \\
\hline \multicolumn{3}{|c|}{$\begin{array}{l}\text { Waist circumference measured below the ribs (usually at the leve } \\
\text { of the navel) }\end{array}$} \\
\hline Men & Women & \\
\hline$<94 \mathrm{~cm}$ & $<80 \mathrm{~cm}$ & 0 \\
\hline $94-102 \mathrm{~cm}$ & $80-88 \mathrm{~cm}$ & 3 \\
\hline$>102 \mathrm{~cm}$ & $>88 \mathrm{~cm}$ & 4 \\
\hline \multicolumn{3}{|c|}{$\begin{array}{l}\text { Do you usually have at least } 30 \text { minutes of physical activity at } \\
\text { work and/or during leisure time (including normal daily activity) } \\
\text { daily? }\end{array}$} \\
\hline \multicolumn{2}{|l|}{ Yes } & 0 \\
\hline \multicolumn{2}{|l|}{ No } & 2 \\
\hline \multicolumn{3}{|c|}{ How often do you eat vegetables, fruit, or berries? } \\
\hline \multicolumn{2}{|l|}{ Every day } & 0 \\
\hline \multicolumn{2}{|l|}{ Not every day } & 1 \\
\hline \multicolumn{3}{|c|}{$\begin{array}{l}\text { Have you ever taken medication for high blood pressure on a } \\
\text { regular basis? }\end{array}$} \\
\hline \multicolumn{2}{|l|}{ No } & 0 \\
\hline \multicolumn{2}{|l|}{ Yes } & 2 \\
\hline \multicolumn{3}{|c|}{$\begin{array}{l}\text { Have you ever been found to have high blood glucose (e.g., in a } \\
\text { health examination, during an illness, during pregnancy)? }\end{array}$} \\
\hline \multicolumn{2}{|l|}{ No } & 0 \\
\hline \multicolumn{2}{|l|}{ Yes } & 5 \\
\hline \multicolumn{3}{|c|}{$\begin{array}{l}\text { Have any of the members of your immediate family or other } \\
\text { relatives been diagnosed with diabetes (type } 1 \text { or type } 2 \text { )? }\end{array}$} \\
\hline \multicolumn{2}{|l|}{ No } & 0 \\
\hline \multicolumn{2}{|c|}{$\begin{array}{l}\text { Yes: grandparent, aunt, uncle, or first } \\
\text { cousin (but not own parent, brother, } \\
\text { sister, } \\
\text { or child) }\end{array}$} & 3 \\
\hline \multicolumn{2}{|c|}{ Yes: parent, brother, sister, or own child } & 5 \\
\hline
\end{tabular}

Risk score: The risk of developing type 2 diabetes within 10 years is:

- < 7 Low: estimated 1 in 100 will develop disease.

- 7-11 Slightly elevated: estimated 1 in 25 will develop disease.

- 12-14 Moderate: estimated 1 in 6 will develop disease.

- 15-20 High: estimated 1 in 3 will develop disease.

- 20 Very high: estimated 1 in 2 will develop disease.

Under aseptic precautions, $\sim 3 \mathrm{~mL}$ blood was collected in an EDTA vacutainer for analysis of HbA1c (whole blood), and $2 \mathrm{~mL}$ blood was collected in a plain red-capped vacutainer (serum was separated by centrifugation at $4000 \mathrm{rpm}$ for 15 minutes) for the estimation of glucose. HbA1c was estimated by ion-exchange high-pressure liquid chromatography
Table 3 Indian Diabetes Risk Score (IDRS) ${ }^{8}$

\begin{tabular}{|c|c|}
\hline Particulars & Score \\
\hline \multicolumn{2}{|l|}{ Age $(y)$} \\
\hline$<35$ & 0 \\
\hline $35-49$ & 20 \\
\hline$>50$ & 30 \\
\hline \multicolumn{2}{|l|}{ Abdominal obesity } \\
\hline $\begin{array}{l}\text { Waist }<80 \mathrm{~cm} \text { (female), }<90 \mathrm{~cm} \\
\text { (male) }\end{array}$ & 0 \\
\hline $\begin{array}{l}\text { Waist > 80-89 cm (female), > } \\
90-99 \mathrm{~cm} \text { (male) }\end{array}$ & 10 \\
\hline $\begin{array}{l}\text { Waist }>80-89 \mathrm{~cm} \text { (female), > } \\
90-99 \mathrm{~cm} \text { (male) }\end{array}$ & 20 \\
\hline \multicolumn{2}{|l|}{ Physical activity } \\
\hline Exercise regular + strenuous work & 0 \\
\hline Exercise regular or strenuous work & 20 \\
\hline No exercise or sedentary work & 30 \\
\hline \multicolumn{2}{|l|}{ Family history } \\
\hline No family history & 0 \\
\hline Either parent & 10 \\
\hline Both parents & 20 \\
\hline Minimum score & 0 \\
\hline Maximum score & 100 \\
\hline
\end{tabular}

Risk score:

$>\geq \mathbf{6 0}$ : Very high risk of having diabetes. Oral Glucose Tolerance Test (OGTT) is recommended to rule out diabetes. If this is not possible, at least a random blood sugar/fasting blood sugar should be done.

$>$ 30-50: The risk of having diabetes is moderate. It is still recommended to have the checkup mentioned in the previous point.

$><30$ : Risk of having diabetes is probably low.

method using Biorad D10 hemoglobin system. Glucose was estimated by the hexokinase method using the fully automated Roche Cobas 6000 integrated system.

\section{Statistical Analysis}

Data analysis was done using SPSS 22/23. Descriptive variables were expressed as mean \pm standard deviation for continuous data and as a ratio for categorical data. Pearson correlation was used to compare continuous variables, with $p$ $<0.05$ considered statistically significant. The optimum cutoff for IDRS, ADA, and FINDRISC was obtained using receiver operative characteristic curve. Sensitivity, specificity, positive predictive value, negative predictive value, positive likelihood ratio, negative likelihood ratio, and Mitchell's clinical utility indices (CUIs) were calculated for each risk tool. Agreement between the different scores in predicting the risk of diabetes mellitus was analyzed by using the BlandAltman approach (B-A plot).

\section{Results and Discussion}

Screening of population using noninvasive diabetes risk scores helps in early identification of prediabetes and diabetes so that the associated complications can be delayed 
or prevented through dietary and lifestyle interventions. Different countries have adopted indigenous risk scores pertaining to their population. Comparison and validation of different risk scores in local population help in identifying the gaps in the respective indigenous risk scores so that suitable modifications can be adapted to enhance the sensitivity of the risk score in screening diabetes.

A total of 160 subjects, who attended MHC/OPD, were recruited for the study and the baseline characteristics of the study subjects is represented in - Table 4 . No significant difference was observed in these variables between diabetic and nondiabetic subjects. It was interesting to note that though $58 \%$ of subjects complied with the physical activity of $>30$ minutes, the number of subjects with normal BMI and those who were overweight was almost equal. It was noted that though $>50 \%$ of subjects in the study group were in the overweight or obese category (based on the BMI cutoff for Indian population-overweight: BMI between 23.0 and $24.9 \mathrm{~kg} / \mathrm{m}^{2}$; and obese: BMI $\geq 25.0 \mathrm{~kg} / \mathrm{m}^{2}$ ), no correlation was observed between BMI and diabetes/HbA1c levels. ${ }^{10-12}$
The distribution of subjects according to ADA/IDRS/ FINDRISC is shown in - Tables $\mathbf{5 , 6}$ and $\mathbf{7}$. The distribution of subjects in the higher risk group was as follows: $20 \%$ as per the ADA risk score ( $>5$ ), $43.12 \%$ as per IDRS ( $>60$ ), and $5 \%$ as per FINDRISC ( $>15)$.

Out of the 160 subjects, 19 were newly diagnosed with diabetes based on fasting blood sugar/random blood sugar and HbA1c as per the ADA criteria. Hence, in our study, we observed that the prevalence of diabetes was $11.9 \%$, which is much higher when compared to the other studies which reported 4.8 and $8.1 \%$ respectively ${ }^{13,14}$ in Maharashtra and the Boloor community in South India. Out of these 19 newly diagnosed diabetics, 11 were above 40 years of age, which reiterates the increased risk of diabetes above 40 years and is in agreement with other studies. ${ }^{5,13}$

The diabetes risk assessment of subjects using the three risk scores is shown in - Table 8. According to IDRS, $42.1 \%$ subjects had a score of $>60$, indicating high risk to diabetes, that is in agreement with other studies, ${ }^{5,8}$ whereas FINDRISC showed no subjects with a score $>15$. This was contradictory

Table 4 Baseline characteristics

\begin{tabular}{|c|c|c|c|c|}
\hline SI. no & Parameters & Characteristics & No. of subjects & $\begin{array}{l}\text { Percentage } \\
\text { (\%) }\end{array}$ \\
\hline \multirow[t]{2}{*}{1.} & \multirow[t]{2}{*}{ Sex } & Male & 81 & 50.6 \\
\hline & & Female & 79 & 49.4 \\
\hline \multirow[t]{5}{*}{2.} & \multirow[t]{5}{*}{ Age (in y) } & $<30$ & 25 & 15.6 \\
\hline & & $30-39$ & 38 & 23.8 \\
\hline & & $40-49$ & 52 & 32.5 \\
\hline & & $50-59$ & 26 & 16.2 \\
\hline & & $>60$ & 19 & 11.9 \\
\hline \multirow[t]{4}{*}{3.} & \multirow[t]{4}{*}{$\mathrm{BMI}\left(\mathrm{kg} / \mathrm{m}^{2}\right)$} & $\begin{array}{l}\text { Underweight } \\
(<18.5)\end{array}$ & 06 & 3.8 \\
\hline & & Normal (18.5-22.9) & 66 & 41.2 \\
\hline & & Overweight (23.0-24.9) & 63 & 39.4 \\
\hline & & Obese $(\geq 25)$ & 25 & 15.6 \\
\hline \multirow[t]{2}{*}{4.} & \multirow[t]{2}{*}{ Blood pressure $(\mathrm{mm} \mathrm{Hg})$} & $<140 / 90$ & 141 & 88.1 \\
\hline & & $>140 / 90$ & 19 & 11.9 \\
\hline \multirow[t]{2}{*}{5.} & \multirow[t]{2}{*}{ Physical activity (min 30 min) } & Yes & 93 & 58.1 \\
\hline & & No & 67 & 41.9 \\
\hline \multirow[t]{4}{*}{6.} & \multirow[t]{4}{*}{ Literacy } & Primary & 18 & 11.3 \\
\hline & & High school & 59 & 36.8 \\
\hline & & Graduation & 63 & 39.4 \\
\hline & & Postgraduation & 20 & 12.5 \\
\hline \multirow[t]{2}{*}{7.} & \multirow[t]{2}{*}{ Locality } & Urban & 93 & 58.1 \\
\hline & & Rural & 67 & 41.9 \\
\hline \multirow[t]{3}{*}{8.} & \multirow[t]{3}{*}{ Habits } & Smoking & 12 & 7.5 \\
\hline & & Alcohol & 18 & 11.2 \\
\hline & & Nonsmokers/Nonalcoholics & 130 & 81.3 \\
\hline \multirow[t]{2}{*}{9.} & \multirow{2}{*}{$\begin{array}{l}\text { Diet (includes fruits and } \\
\text { vegetables) }\end{array}$} & Yes & 139 & 86.9 \\
\hline & & No & 21 & 13.1 \\
\hline
\end{tabular}

Abbreviation: BMI, body mass index. 
to the study done by Pawar et al, who observed $12.6 \%$ subjects with a score $>15 .{ }^{13}$ In addition, no statistically significant differences were observed among the high- and low-risk categories based on IDRS and FINDRISC. ${ }^{13}$ However, in our study, as per the classification based on the ADA risk score, diabetic subjects with scores $<5$ and $\geq 5$ were 63.2 and $36.8 \%$, respectively. In addition, ADA risk score was the only risk score that showed statistically significant difference ( $p$-value of 0.05 ) between low- and high-risk subjects. The odds of being affected by diabetes were calculated with respect to people in the high-risk categories with their diabetic status. Individuals with high risk by ADA ( $>5$ ) were 2.70 times more likely (95\% confidence interval: $0.97-7.56$ ) to be affected by diabetes than individuals without high risk; however, the other two risk scores failed to show any significant difference.

Table 5 Classification of subjects according to IDRS

\begin{tabular}{|l|l|l|}
\hline IDRS & Frequency & Percentage (\%) \\
\hline Low risk (0-29) & 13 & 8.13 \\
\hline Moderate risk (30-59) & 78 & 48.75 \\
\hline High risk (> 60) & 69 & 43.12 \\
\hline Total & 160 & \\
\hline
\end{tabular}

Abbreviation: IDRS, Indian Diabetes Risk Score.

Table 6 Classification of subjects according to ADA

\begin{tabular}{|l|l|l|}
\hline ADA risk score & Frequency & Percentage (\%) \\
\hline$<\mathbf{5}$ & 128 & 80.0 \\
\hline$\geq \mathbf{5}$ & 32 & 20.0 \\
\hline
\end{tabular}

Abbreviation: ADA, American Diabetic Association.

Table 7 Classification of subjects according to FINDRISC

\begin{tabular}{|l|l|l|}
\hline FINDRISC & Frequency & Percentage (\%) \\
\hline Low (0-6) & 81 & 50.63 \\
\hline Slightly elevated (7-11) & 54 & 33.75 \\
\hline Moderate (12-14) & 17 & 10.62 \\
\hline High (15-20) & 06 & 3.75 \\
\hline Very high (>20) & 02 & 1.25 \\
\hline
\end{tabular}

Abbreviation: FINDRISC, Finnish Diabetes Risk Score.
Hence, in our study, ADA risk score was superior in screening the risk group than the other two risk scores.

According to a CURES study, IDRS has a sensitivity of $72.5 \%$, specificity of $60.1 \%$, and is derived based on the largest population-based study on diabetes in India. In addition, some recent studies showed a significantly higher sensitivity and specificity, ${ }^{8,14}$ whereas our study observed a stark difference, with much lower sensitivity of $42.11 \%$ and specificity of $56.74 \%$. On the other hand, the specificity observed in our study is aligned with the study done by Sowmiya et al. ${ }^{15}$ The possible reasons might be a smaller sample size, no significant difference in the percentage of normal and overweight subjects, and family history provided by study subjects.

In comparison to the IDRS sensitivity and specificity levels, FINDRISC showed a specificity of $94.33 \%$, whereas the risk score failed to identify true positive diabetes cases in our study group representing South Indian population. However, studies have shown significant sensitivity and specificity with the FINDRISC score. ${ }^{16,17}$ A probable reason for this disparity might be the variation in dietary habits that are not applicable to our local population, apart from being influenced by a lower socioeconomic status.

Our study observed that ADA risk score assessment had the highest positive and negative predictive values when compared with IDRS and FINDRISC, as shown in - Table 9. Further, between IDRS and FINDRISC assessments, IDRS has higher positive and negative predictive levels.

Diagnostic accuracy was measured by using the following cutoff: $A D A \geq 5$, IDRS > 60, and FINDRISC > 15. Accuracy in detecting the nondiabetic or lower-risk group is as follows: FINDRISC is $83.12 \%$, when compared with IDRS (55\%) and ADA (76.88\%), as shown in - Table 10. Our findings are in alignment with other study groups who have recommended the usage of FINDRISC for "ruling out" rather than "ruling in" diabetes. ${ }^{13}$

As shown in - Fig. 1, area under the curve (AUC) was largest for ADA (0.496) when compared with IDRS and FINDRISC, though there was no statistically significant difference between ADA and the other two risk scores. The AUC for ADA risk score in our study was lower when compared with 0.668 observed in Boloor community and 0.882 in Sharma et al. ${ }^{14,18}$

Table 8 Distribution of IDRS, ADA, and FINDRISC cutoff risk scores for diagnosis of diabetes among study subjects

\begin{tabular}{|c|c|c|c|c|c|c|c|}
\hline \multicolumn{2}{|c|}{ Risk scores } & \multicolumn{2}{|c|}{ Nondiabetic } & \multicolumn{2}{|l|}{ Diabetic } & \multirow[t]{2}{*}{ Chi-squared } & \multirow[t]{2}{*}{$p$-Value } \\
\hline & & Frequency & $\%$ & Frequency & $\%$ & & \\
\hline \multirow[t]{2}{*}{ IDRS } & $<60$ & 80 & $56.7 \%$ & 11 & 57.9 & \multirow[t]{2}{*}{0.009} & \multirow[t]{2}{*}{0.924} \\
\hline & $>60$ & 61 & $43.3 \%$ & 8 & 42.1 & & \\
\hline \multirow[t]{2}{*}{ ADA } & $<5$ & 116 & $82.3 \%$ & 12 & 63.2 & \multirow[t]{2}{*}{3.822} & \multirow[t]{2}{*}{$0.05^{\circ}$} \\
\hline & $\geq 5$ & 25 & $17.7 \%$ & 7 & 36.8 & & \\
\hline \multirow[t]{2}{*}{ FINDRISC } & $<15$ & 133 & $94.3 \%$ & 19 & 100.0 & \multirow[t]{2}{*}{1.13} & \multirow[t]{2}{*}{0.287} \\
\hline & $>15$ & 8 & $5.7 \%$ & 0 & 0.0 & & \\
\hline
\end{tabular}

Abbreviations: ADA, American Diabetic Association; FINDRISC, Finnish Diabetes Risk Score; IDRS, Indian Diabetes Risk Score.

Note: ${ }^{*} p \leq 0.05$ : statistically significant. 
Table 9 Comparison of characteristics of the three screening test scores

\begin{tabular}{|c|c|c|c|c|c|c|}
\hline \multirow[t]{2}{*}{ Screening characteristic } & \multicolumn{2}{|c|}{ IDRS (> 60) } & \multicolumn{2}{|c|}{$\operatorname{ADA}(\geq 5)$} & \multicolumn{2}{|c|}{ FINDRISC (> 15) } \\
\hline & Value & $95 \% \mathrm{Cl}$ & Value & $95 \% \mathrm{Cl}$ & Value & $95 \% \mathrm{Cl}$ \\
\hline Sensitivity (\%) & 42.11 & $20.25-66.5$ & 36.84 & $16.29-61.64$ & 0.00 & $0.00-17.65$ \\
\hline Specificity (\%) & 56.74 & $48.14-65.05$ & 82.27 & $74.95-88.18$ & 94.33 & $89.13-97.52$ \\
\hline Positive likelihood ratio & 0.97 & $0.56-1.70$ & 2.08 & $1.04-4.13$ & 0.00 & - \\
\hline Negative likelihood ratio & 1.02 & $0.68-1.54$ & 0.77 & $0.542-1.09$ & 1.06 & $1.02-1.10$ \\
\hline PPV (\%) & 11.59 & $6.97-18.67$ & 21.87 & $12.34-35.77$ & 0 & - \\
\hline NPV (\%) & 87.91 & $82.84-91.64$ & 90.62 & $87.18-93.22$ & 87.5 & $87.05-87.94$ \\
\hline Accuracy (\%) & 55 & $46.95-62.86$ & 76.88 & $69.56-83.17$ & 83.12 & $76.41-88.57$ \\
\hline AUC & 0.467 & $0.329-0.605$ & $0.496^{*}$ & $0.350-0.643$ & 0.454 & $0.332-0.577$ \\
\hline
\end{tabular}

Abbreviations: ADA, American Diabetic Association; AUC, areas under the curve; Cl, confidence interval; FINDRISC, Finnish Diabetes Risk Score; IDRS, Indian Diabetes Risk Score; PPV, positive predictive value; NPV, negative predictive value.

Table 10 Clinical Utility Index (CUI)

\begin{tabular}{|l|l|l|l|}
\hline Score name & CUI & Values & Qualitative grades \\
\hline \multirow{2}{*}{ ADA risk score } & $\mathrm{CUI}^{+}$ & 0.136 & Very poor \\
\cline { 2 - 4 } & $\mathrm{CUI}^{-}$ & 0.849 & Excellent \\
\hline \multirow{2}{*}{ IDRS } & $\mathrm{CUI}^{+}$ & 0.177 & Very poor \\
\cline { 2 - 4 } & $\mathrm{CUI}^{-}$ & 0.861 & Excellent \\
\hline
\end{tabular}

Abbreviations: ADA, American Diabetic Association; IDRS, Indian Diabetes Risk Score.

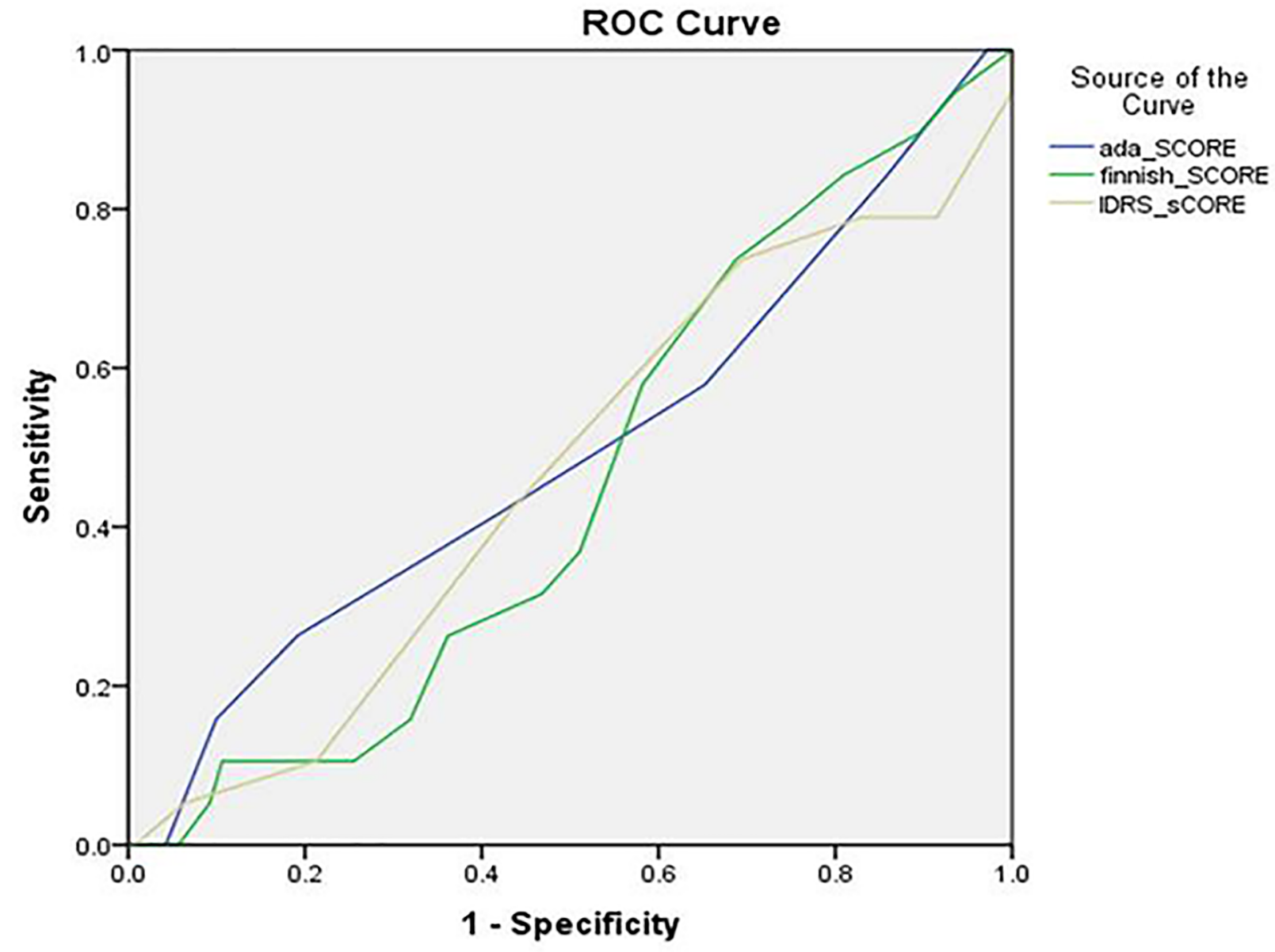

Diagonal segments are produced by ties.

Fig. 1 Comparison of receiver operative characteristic (ROC) curves of Indian Diabetes Risk Score (IDRS), American Diabetes Association (ADA), and Finnish Diabetes Risk Score (FINDRISC). 
A B-A plot was used to assess the level of agreement between ADA and IDRS for stratifying the risk of diabetes, as shown in -Fig. 2 . We found a good agreement between the two risk scores. FINDRISC was not included, as it was unable to identify the diabetes positive cases.

CUI was calculated to measure the clinical relevance of the three risk scores in the local population. Since FINDRISC failed to identify the diabetes positive cases, CUI was calculated only for ADA and IDRS, as shown in - Table 10. CUI assessments showed that both risk scores were poor in case finding but excellent in ruling out diabetes in the healthy population. To our knowledge, we could find only one study in alignment with our observations regarding CUI. ${ }^{13}$

We also compared the applicability of all three risk scores in detecting prediabetes cases. In our study, only ADA risk score demonstrated the ability to detect prediabetic subjects in the study population, which was statistically significant $(p$-value $=0.001)$, as shown in - Table 11 . Our findings are in agreement with the study done by Prabhu et al. ${ }^{19}$

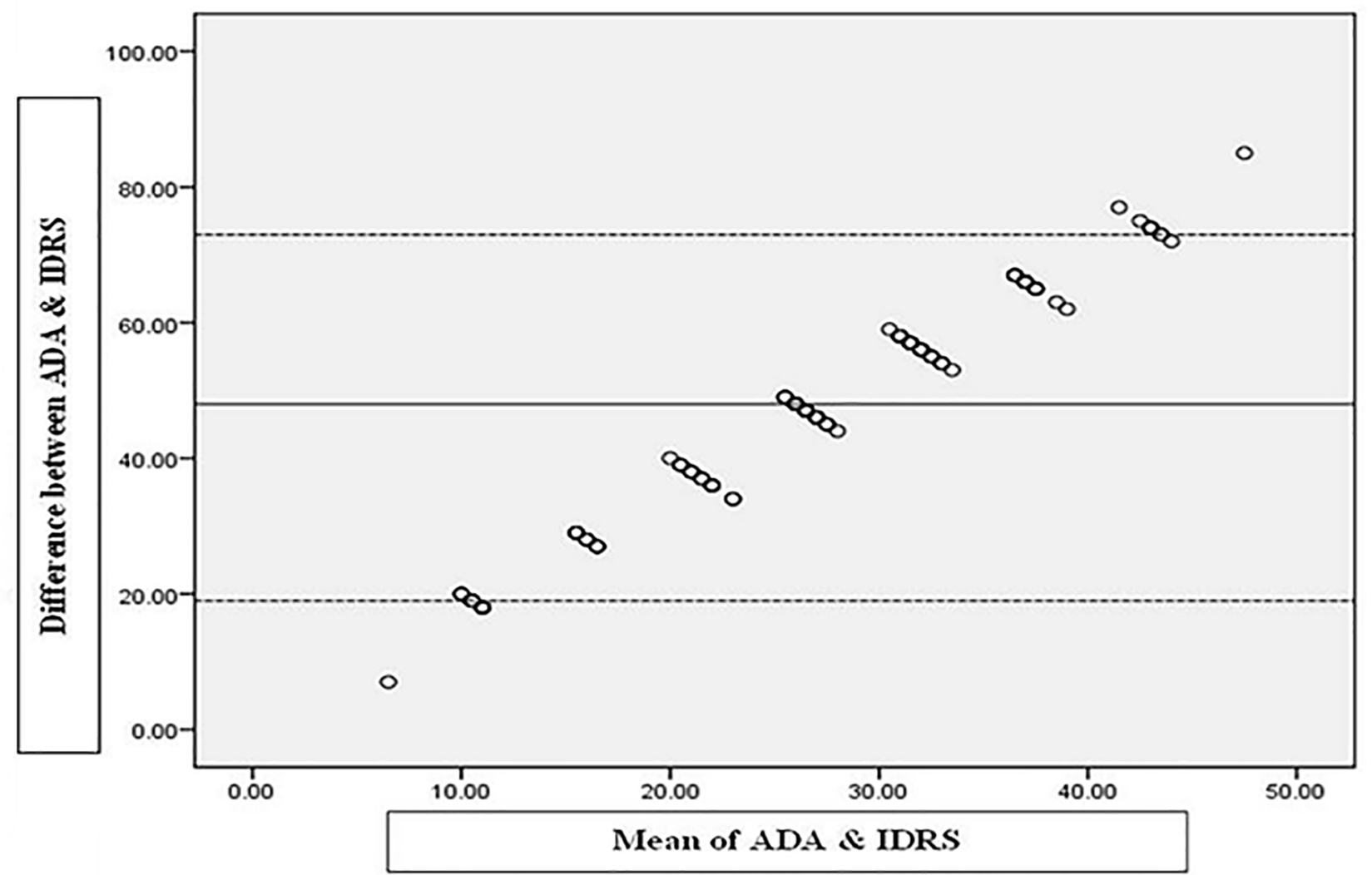

Fig. 2 Bland-Altman plot for assessing the agreement between Indian Diabetes Risk Score (IRDS) and American Diabetes Association (ADA) risk score.

Table 11 Distribution of IDRS, ADA, and FINDRISC cutoff risk scores for diagnosis of prediabetes among study subjects

\begin{tabular}{|c|c|c|c|c|c|c|c|}
\hline \multicolumn{2}{|c|}{ Risk scores } & \multicolumn{2}{|c|}{ Nondiabetic } & \multicolumn{2}{|l|}{ Diabetic } & Chi-squared & $p$-Value \\
\hline & & \multirow{2}{*}{$\begin{array}{l}\text { Frequency } \\
42\end{array}$} & \multirow{2}{*}{\begin{tabular}{l|l|}
$\%$ \\
51.2 \\
\end{tabular}} & \multirow{2}{*}{$\begin{array}{l}\text { Frequency } \\
49\end{array}$} & \multirow{2}{*}{$\begin{array}{l}\% \\
62.8\end{array}$} & & \\
\hline IDRS & $<60$ & & & & & 2.193 & 0.139 \\
\hline & $>60$ & 40 & 48.8 & 29 & 37.2 & & \\
\hline \multirow[t]{2}{*}{ ADA } & $<5$ & 57 & 69.5 & 71 & 91 & \multirow[t]{2}{*}{11.563} & \multirow[t]{2}{*}{$0.001^{*}$} \\
\hline & $\geq 5$ & 25 & 30.5 & 7 & 9.0 & & \\
\hline \multirow[t]{2}{*}{ FINDRISC } & $<15$ & 77 & 93.9 & 75 & 96.2 & \multirow[t]{2}{*}{0.427} & \multirow[t]{2}{*}{0.514} \\
\hline & $>15$ & 5 & 6.1 & 3 & 3.8 & & \\
\hline
\end{tabular}

Abbreviations: ADA, American Diabetic Association; FINDRISC, Finnish Diabetes Risk Score; IDRS, Indian Diabetes Risk Score.

Note: ${ }^{*} p \leq 0.05$ : statistically significant. 


\section{Conclusion}

Our study showed that ADA was in agreement with and was found to be a better risk score for assessing diabetes in the current study population, which could be due to the inclusion of the history of gestational diabetes as one of the variables in its screening criteria. Though our recommendation would be to use ADA risk score or IDRS for screening diabetes in the South Indian population, the comparison needs to be validated in a larger population, considering all the pertinent variables affecting the diagnosis of diabetes. Furthermore, we would suggest that the inclusion of the history of gestational diabetes and hypertension in IDRS might improve its sensitivity as a screening tool in our local population.

\section{Conflicting Interest \\ None. \\ Source(s) of Support \\ Study approved under ICMR-STS 2019.}

\section{Presentation at a Meeting}

None.

\section{References}

1 Dudeja P, Singh G, Gadekar T, Mukherji S. Performance of Indian Diabetes Risk Score (IDRS) as screening tool for diabetes in an urban slum. Med J Armed Forces India 2017;73(2):123-128

2 International Diabetes Federation. IDF Diabetes Atlas, 9th edition. Brussels, Belgium: International Diabetes Federation; 2019. http://www.diabetesatlas.org. Accessed September 25, 2020

3 Nagalingam S, Sundaramoorthy K, Arumugan B. Screening for diabetes using Indian Diabetes Risk Score. Indian J Adv Med 2016;3(2):415-418

4 Omech B, Mwita JC, Tshikuka J-G, Tsima B, Nkomazna O, Amone-P'Olak K. Validity of the Finnish Diabetes Risk Score for detecting undiagnosed type 2 diabetes among general medical outpatients in Botswana. J Diabetes Res 2016;2016:4968350

5 Woo YC, Lee CH, Fong CHY, Tso AWK, Cheung BMY, Lam KSL. Validation of the diabetes screening tools proposed by the American Diabetes Association in an aging Chinese population. PLoS One 2017;12(9):e0184840

6 Bernabe-Ortiz A, Perel P, Miranda JJ, Smeeth L. Diagnostic accuracy of the Finnish Diabetes Risk Score (FINDRISC) for undiagnosed T2DM in Peruvian population. Prim Care Diabetes 2018;12(6):517-525
7 Joshi SR. Indian Diabetes Risk Score. J Assoc Physicians India 2005;53:755-757

8 Mohan V, Deepa R, Deepa M, Somannavar S, Datta M. A simplified Indian Diabetes Risk Score for screening for undiagnosed diabetic subjects. J Assoc Physicians India 2005;53:759-763

9 American Diabetes Association. Classification and diagnosis of diabetes: standards of medical care in diabetes-2020. Diabetes Care 2020;43(Suppl 1) :S14-S31

10 Aziz N, Kallur SD, Nirmalan PK. Implications of the revised consensus body mass indices for Asian Indians on clinical obstetric practice. J Clin Diagn Res 2014;8(5):OC01-OC03

11 Bays HE, Chapman RH, Grandy S; SHIELD Investigators' Group. The relationship of body mass index to diabetes mellitus, hypertension and dyslipidaemia: comparison of data from two national surveys [published correction appears in Int J. Clin Pract 2007;61(10):1777-1778

12 Bae JP, Lage MJ, Mo D, Nelson DR, Hoogwerf BJ. Obesity and glycemic control in patients with diabetes mellitus: analysis of physician electronic health records in the US from 2009-2011. J Diabetes Complications 2016;30(2):212-220

13 Pawar SD, Naik JD, Prabhu P, Jatti GM, Jadhav SB, Radhe BK. Comparative evaluation of Indian Diabetes Risk Score and Finnish Diabetes Risk Score for predicting risk of diabetes mellitus type II: a teaching hospital-based survey in Maharashtra. J Family Med Prim Care 2017;6(1):120-125

14 Adhikari P, Pathak R, Kotian S. Validation of the MDRF-Indian Diabetes Risk Score (IDRS) in another South Indian population through the Boloor Diabetes Study (BDS). J Assoc Physicians India 2010;58:434-436

15 Sowmiya KR, Balaji SM, Arumugam B, Mohanan S. Indian Diabetic Risk Score-a screening tool for detecting type 2 diabetes mellitus at the primary health care level. Natl J Res Community Med 2017;6(1):69-72

16 Vandersmissen GJM, Godderis L. Evaluation of the Finnish Diabetes Risk Score (FINDRISC) for diabetes screening in occupational health care. Int J Occup Med Environ Health 2015; 28(3):587-591

17 Chaturvedi M, Pandey A, Javed M, Baiswar R. Validity of Indian Diabetes Risk Score (IDRS) in population in and around Agra. J Assoc Physicians India 2018;66(10):33-35

18 Sharma KM, Ranjani H, Nguyen H, et al. Indian Diabetes Risk Score helps to distinguish type 2 from non-type 2 diabetes mellitus (GDRC-3). J Diabetes Sci Technol 2011;5(2):419-425

19 Prabhu G, Poovitha M, Jayasri S. To determine the usefulness of ADA risk score to predict T2dm/prediabetes in South Indian rural population. Int J Contemporary Med Res 2019; 6(8):H27-H30 